\title{
A IDEOLOGIA DO CONSUMISMO
}

\author{
Lindomar Teixeira Luiz
}

Professor da UNOESTE e Doutorando em Serviço Social pela UNESP de Franca. lindomar@fai.com.br

\begin{abstract}
RESUMO
O consumismo é uma das características marcantes da sociedade. Sua principal função se volta para a própria essência do capitalismo, ou seja, a venda de produtos e serviços com vistas à apropriação do lucro. Ocorre que, se a ideologia do consumo se vincula a interesses mercadológicos, o seu grande sucesso, bem como suas conseqüências, transcendem questões de natureza meramente econômica. Nesse sentido, a proposta do presente artigo é discutir alguns elementos que permeiam a lógica do consumo na sociedade capitalista e algumas de suas conseqüências.
\end{abstract}

Palavras-chave: Ideologia - Consumismo - Cultura de Massas - Capitalismo

\section{THE IDEOLOGY OF CONSUMPTION}

\section{ABSTRACT}

Consumption is one of the marked characteristics of society. Its main function is turned to its own capitalism essence, that is, the selling of products and services aiming the appropriation of profit. It occurs that if the ideology of consumption is linked to marked interests, its great sucess, as well as suas consequences, transcends questions of mere economical nature. On this sense, the proposal of the present article is discuss some elements that are linked to the logical of consuption on the capitalist society and some of its consequences.

Key words Ideology - Consumption - Mass Culture - Capitalism 
É assaz comum associar o consumismo ao capitalismo, pois ambos quase que se confundem. Não obstante, antes do advento da sociedade capitalista tivemos alguns pressupostos do consumismo: a cultura do consumo. Tal cultura é evidenciada com a aristocracia da Europa. Os aristocratas, como se sabe, viviam do arrendamento das terras e atuavam nas atividades da guerra, que eram tidas como honrosas; além disso, neste segmento social o consumo do luxo e a sua ostentação eram bastante comuns.

Com o advento do capitalismo surge, por volta do século $\mathrm{XV}$, na Europa, uma outra classe dominante: a burguesia. Esta se inspirou no universo aristocrata para construir os seus valores. Assim, o consumo conspícuo das classes burguesas não emana apenas em função da sua riqueza: a referida classe absorve o ideário aristocrata, que proporcionava reconhecimento e o prestígio. Não obstante, os burgueses recusam a extravagância aristocrática. Entretanto, o luxo, o consumo e a ostentação passam a fazer parte do universo burguês.

Nesta perspectiva, se consumo burguês se efetua pela sua riqueza, ele a transcende e não se limita à satisfação de necessidades; é conveniente, portanto, utilizarmos a categoria consumismo (ideologia do consumismo), pois esta contempla aspectos subjetivos e culturais assaz acentuados. Nesse sentido, um importante itinerário para se pensar o consumismo é através da cultura de massas. O que é cultura de massas ? Nas palavras de Morin ${ }^{1}$ :.

"um corpo complexo de normas, símbolos e imagens (...)" derivadas da imprensa, do

\footnotetext{
${ }^{1}$ MORIN, Edgard. Cultura de Massas no Século XX.RJ: Forense,1967, p.16
}

cinema, do rádio, da televisão (...)" produzida segundo normas maciças da fabricação industrial (...) destinando-se a uma massa social, isto é, um aglomerado gigantesco de indivíduos compreendidos aquém e além das estruturas internas da sociedade"

A própria definição acima ressalta que o fulcro da cultura de massas está intrinsecamente ligado ao consumismo. O sistema capitalista necessita não somente de um aparato infra-estrutural (produção, mão-deobra, tecnologia, etc.), mas precisa de instrumentos que irão conquistar a dimensão subjetiva e valorativa com $o$ intuito de convencer o sujeito a consumir produtos e serviços.

Desta forma, a cultura de massas penetra na intimidade das pessoas, fundamentalmente através da identificação e da projeção. A identificação é tão-somente o processo pelo qual o sujeito se assemelha a determinados conteúdos da cultura de massas; enquanto a projeção seria o processo em que o sujeito se lança em situações agradáveis ocorridas nos conteúdos da cultura de massas. Através da identificação e da projeção é que os produtos e serviços, veiculados pela cultura de massas, estarão inseridos em um universo repleto de valores e situações enaltecedoras e prazerosas, fazendo com que aquilo que se intenciona vender venha carregado de uma gama de simbolismo, isto é, determinados produtos e serviços representam aquelas situações ideais, tanto do ponto de vista dos valores quanto do prazer. É perceptível, nesta perspectiva, que as propagandas veiculadas pela televisão, não tenham apenas a função de vender produtos e serviços, elas acabam transmitindo padrões de situações tidas com 
ideais, sejam em termos de valores (estéticos, morais, etc), sejam em termos de satisfação. Diz Ciro ${ }^{2}$ :

"Essa função reforçadora da publicidade é seu suporte para a venda de mercadorias pois, ao mesmo tempo que incita ao consumo, é o próprio veículo o transporte dos valores e dos desejos que estão ancorados na cultura que se consome. As mercadorias trazem em si, incorporado, tudo aquilo que a sociedade deseja, e por isso são consumidas".

Com base na reflexão acima citada, podemos questionar a idéia de que na sociedade impera, de forma absoluta, um utilitarismo - capitalista - que se confunde com a ideologia consumista. De fato existe uma pujante tendência da postura utilitarista na sociedade capitalista, ou seja, aquilo que não é útil para o capital - leia-se não gera lucro - é tido como desnecessário; o que é importante para o capital - não é erradicar aquilo que oprime, frustra ou causa sofrimento ao homem, mas sim aquilo que serve aos interesses do capital. Um exemplo: enquanto grandes grupos econômicos capitalistas estiverem ganhando com inúmeros impactos ambientais, estes não deixarão de existir por muito tempo. O que está em jogo é manutenção da lógica do capital que, como sabemos, favorece apenas uma minoria.

Nosso questionamento acerca de utilitarismo burguês está baseado na seguinte idéia: se para o capital tudo é lucro, isto não ocorre para o ser humano que possui necessidades e interesses que transcendem o pragmatismo utilitarista do capitalismo. Desta forma, para o capital, as propagandas de produtos e serviços são estruturadas em uma

\footnotetext{
${ }^{2}$ CIRO Marcondes Filho. A televisão: a vida pelo vídeo.SP: Moderna, 1993. p.78
}

unidimensionalidade: o utilitarismo burguês voltado para a apropriação do lucro. Diferentemente para o indivíduo, que internaliza determinada propaganda: para este, aquilo que a propaganda exibe transcende o utilitarismo do capital no instante em que o sujeito, ao se identificar ou se projetar em tais universos, mergulha numa dimensão subjetiva e valorativa que não são nada pragmáticos. Assim, por exemplo, o sujeito que compra um carro, não está apenas adquirindo um meio de transporte, pois tal automóvel representa prestígio, reconhecimento, conforto, segurança para sua família etc. Desta maneira, é como se o capital utilizasse do universo subjetivo valorativo para implementar seus interesses utilitaristas. Poderíamos estender nosso argumento para o futebol, o romance, os dias feriados, a arte etc: tudo isto nos parece que, pelo menos diretamente, não se enquadram na lógica utilitarista à medida que contemplam um sentido simbólico para as pessoas. Entretanto, o capital preserva o utilitarismo, porém encorpora, na lógica utilitária do consumo, elementos que compõem um universo nada utilitário. Um exemplo: o futebol, que tem um significado simbólico para o indivíduo, não se enquadra diretamente na lógica do utilitarismo por nada produzir, contudo, é de conhecimento notório que grandes empresas investem vultuosos recursos neste esporte visando à venda de produtos e serviços.

Em suma, o consumismo veiculado pela cultura de massas é poderoso não apenas pelo fato de concretizar o lucro capitalista, mas de contemplar outros elementos que habitam a dimensão valorativa e subjetiva das pessoas. Com tais argumentos 
não queremos afirmar a inexistência do utilitarismo consumista no cotidiano das pessoas, pelo contrário: existe um intrínseco envelhecimento precoce dos produtos e serviços que tem a ver com a lógica lucrativa do consumismo utilitarista. É de conhecimento notório a rapidez com que se torna obsoleto uma infinidade de bens de consumo e de serviços. A informática pode ser discutida como um exemplo: em poucos meses certos equipamentos já se tornam "jurássicos", isto é, podem funcionar perfeitamente. Todavia, o mercado os aposenta, lançando novos produtos. É como se tudo fosse descartável: usa e joga fora. Tal postura vem se infiltrando entre as pessoas. Isto ocorre à medida que o outro passa a ser objeto de uso descartável. O exemplo disto talvez seja o "ficar" para as gerações mais jovens, em que não há compromisso nenhum de ambas as partes.

Há um outro caminho para se pensar como a lógica do utilitarismo capitalista é limitada quando se restringe à funcionalidade do lucro: o valor dos produtos e dos serviços. Obviamente, que pela lógica utilitarista, o valor de troca é imprescindível para o capital, ao passo que o valor do uso é priorizado pelo consumidor. Nesse sentido, em sua forma clássica, o valor de algo tem a ver com o trabalho social contido em determinado produto, bem como a sua procura pelos consumidores. Esta assertiva não é falsa, porém, há outros elementos que estão permeados na questão do valor. Assim, pela lógica do consumismo, o valor dos produtos depende cada vez menos daquilo que o sujeito pensa, e sim da propaganda e do parecer dos "especialistas" sobre qualquer assunto. Um exemplo: um carro é tido como bom se a propaganda convence o sujeito e se os mais "entendidos" disserem o mesmo; outro exemplo: será que se degusta bebidas alcoólicas e refrigerantes, de determinadas marcas, pela qualidade destes produtos ou porque determinados indivíduos externam o seu parecer positivo sobre os mesmos?

A ideologia do consumismo contribui para a manutenção das estruturas do sistema capitalista não apenas através do lucro, mas funciona como um mecanismo de aceitação das pessoas às conturbadas e difíceis condições sob as quais se vive. É bem possível que as condições adversas, em que a grande maioria do povo vive, sejam aceitas por se vislumbrar a possibilidade de se ter acesso aos bens e serviços oferecidos pelo sistema. Em outras palavras, aceita-se a humilhação do chefe, sofre-se em ônibus apertados, come-se mal, trabalha-se cansado etc., com a intenção de receber o salário, ao final do mês, que permite a compra do CD do cantor preferido, a televisão nova, o forno de microondas, o DVD, o automóvel etc. Não é somente isto. As pessoas se sentem reconhecidas com a aquisição de certos bens, pois a própria ideologia do consumismo reforça a máxima liberal "ter" para "ser"; não se pode esquecer do prazer prometido por tais produtos, que tem também a função de compensar e fugir da dor e do sofrimento que são constantes em nossa sociedade. Nesse sentido, um fragmento da música do grupo Titãs é elucidativo: "...a gente quer prazer para aliviar a dor". Cabe lembrar, também, que o consumismo provavelmente pode estar ligado a um enaltecimento, de natureza moral, inerente ao fato do sujeito prover os bens materiais e simbólicos para os membros da 
sua família: é o que a antropóloga Sarti ${ }^{3}$ chama de "ética de provedor".

Ainda sobre a questão de manutenção da sociedade via consumismo, Cristovam Buarque ressalta que um grande entrave para acabarmos com a pobreza, em nosso país, está ligado a um imaginário social que prioriza a riqueza e o consumo, ao invés de se preocupar com bens e serviços necessários para se garantir a melhora na qualidade de vida do povo. Além disso, o referido imaginário é captado por governos, que acabam efetuando um trabalho nesta perspectiva, ou seja, priorizando aquilo que é supérfluo. Nas palavras de Buarque ${ }^{4}$ :

"O maior entrave à erradicação da pobreza está no fato de o brasileiro deseja ser rico antes mesmo de deixar de ser pobre. Deseja mais um carro para cada um do que educação para todas as crianças e saúde para todas as famílias. Prefere viadutos a saneamento".

"Criou-se na população um padrão de sonhos: alto consumo, em vez do atendimento das necessidades essenciais. Isto formou um imaginário que decide as eleições públicas, que orienta a economia e que na busca do aumento da riqueza, torna-se incapaz de reduzir a pobreza"

Assim, o que Buarque chama de imaginário social, acerca da riqueza e do consumo, tem tudo a ver com a ideologia do consumismo: esta não está em sintonia com as necessidades sociais da grande maioria, mas, se converge para produtos e serviços nem tão necessários para quem os consome. O mesmo raciocínio pode ser utilizado para a questão da saúde, isto é, pensa-se que o

\footnotetext{
${ }^{3}$ SARTI, Cinthya. A Família Como Espelho. SP: Cortez, 2003.

${ }^{4}$ BUARQUE, Cristovam. Os Instrangeiros. Petrópolis:Garamonte, 2002 p.77-78.
}

consumo de produtos e serviços médicohospitalares garantem melhor saúde, ao invés de se contemplar transformações sociais com vistas a melhorar a qualidade de vida do povo.

Paradoxalmente, a ideologia do consumismo pode contribuir para acentuar conflitos, seja num plano individual, seja numa dimensão classista. Como? À medida que a motivação do indivíduo é o desejo de consumo e ele não tem recursos suficientes para tal realização, este pode vir a efetuar práticas ilícitas, criminosas e violentas com vistas à concretização de seus objetivos. O tráfico de drogas e a grande criminalidade dos grandes centros - entre outras coisas - tem a ver com o desejo de se ter acesso as maravilhas confeccionadas pela sociedade capitalista, isto é, a recusa em se aceitar baixos salários ou o subemprego não é apenas motivada pela dificuldade de se garantir o mínimo para a sobrevivência material: quanto menos recursos, mais longe se está do universo de consumo. Por outro lado, sabe-se que apenas $1 / 3$ da população efetivamente consome determinados produtos e serviços, o que não oblitera a pujança da ideologia do consumismo à medida que existem inúmeros produtos por preços irrisórios: os "camelódromos" e as lojas de $R \$ 1,99$ fazem muito sucesso nos segmentos mais pobres da sociedade.

Quanto ao conflito de natureza classista, pode ter alguma coisa a ver com a ideologia do consumismo? É evidente que as classes favorecidas procurarão manter uma estrutura de sociedade com vistas à manutenção dos seus privilégios - um deles é o consumo - e a garantia de sua segurança. Entretanto, gostaríamos de ressaltar algo menos evidente: o preconceito e a intolerância aos que não consomem. Parece-nos que 
àqueles que não tem acesso ao consumo de determinados bens não são reconhecidos como seres humanos, é um "ter" para "ser" radicalizado. Daremos dois exemplos. Primeiro: há alguns anos atrás, em Brasília, jovens de classes favorecidas, atearam fogo em um índio, que dormia na rua Os referidos jovens imaginam que fosse um mendigo, ou seja, se é mendigo não consome, se não consome não é gente, logo, deve ser destruído como se fosse objeto.

Segundo exemplo: sabe-se que há fortunas que foram conseguidas sob o roubo, tráfico de drogas e corrupção. Pois bem, quando se tem o dinheiro, o sujeito pode ser idiota, inculto e deselegante, porém o tratamento que se tem para com o sujeito de posses é de reverência, respeito e adoração. Porém, quando não se tem o dinheiro o sujeito é simplesmente um objeto. Assim, em uma sociedade dominada pelo dinheiro, e pela ideologia do consumo, tudo se inverte. Diz Marx ${ }^{5}$ :

"O dinheiro é o bem supremo, logo, é bom seu possuidor, o dinheiro poupa-me além disso do trabalho de ser desonesto, logo, presume-se que sou honesto; sou estúpido, mas o dinheiro é o espírito real de todas as coisas, como poderia seu possuidor ser um estúpido ? Além disso, seu possuidor pode comprar as pessoas inteligentes e quem tem poder sobre os inteligentes não é mais inteligente que o inteligente ? "

Além disso, a ostentação material motivada pela ideologia do consumismo pode sinalizar um grande vazio intelectualexistencial dos agentes exibicionistas (sejam eles de quaisquer classes), pois é sabido que aquele que exibe em demasia algo, não acredita realmente naquilo que transmite para o outro. Sendo assim, a riqueza material pode ser um prêmio, mas um prêmio de consolação.

Assim, a ideologia de consumismo diz muito da nossa sociedade, porém de forma subjacente: ela não fala apenas da riqueza presente nos produtos e serviços consumidos, mas expõe as várias faces da dimensão afetiva valorativa - seja do indivíduo, seja da sociedade - presentes no universo real e irreal do consumo.

\section{BIBLIOGRAFIA}

BUARQUE, Cristovam. Os Instrangeiros.

Petrópolis:Garamonte, 2002.

CIRO, Marcondes. A televisão: a vida pelo vídeo.SP: Moderna, 1993.

MORIN, Edgard. Cultura de Massas no Século XX.RJ: Forense,1967.

MARX, Karl. Manuscritos Econômico-

Filosóficos. SP: Nova cultural, 1991.

ROUANET, Sérgio Paulo. Teoria Crítica e Psicanálise. Rio de Janeiro: Tempo Brasileiro, 1986.

Mal estar na Modernidade. São Paulo: Companhia da Letras, 1993.

SARTI, Cinthya. A Família Como Espelho. SP: Cortez, 2003.

\footnotetext{
${ }^{5}$ MARX, Karl. Manuscritos econômico-filosóficos. SP:Nova cultural, 1991.
} 